\title{
Whose Sentence Is It? \\ The Effects of Parental Incarceration on the Academic Lives of Children - A Review of the Literature
}

\author{
Ashling Ryan-Mangan \\ Trinity College Dublin
}

\begin{abstract}
Children of incarcerated parents are considered to be more at risk socially, emotionally, economically and mentally than their counterparts. Despite the growing international interest in these issues, there appears to be a dearth of research from an educational perspective. This article explores how the direct and indirect effects of parental incarceration can have an impact on a child's academic life and also discusses possible moderating factors by means of a review of existing literature.
\end{abstract}

\section{Introduction}

When a parent is imprisoned there can be farreaching effects on a child's life. Some of these effects can stem directly from the absence of the parent, while others can exert an indirect influence through a variety of ways. The impact of parental incarceration on a child's academic life is something that has received little attention in the past, and yet can be considered to influence significantly the life chances of a child. It is important to note, from the outset, that not every child who has a parent in prison suffers as a result of this. This brief article, nonetheless, seeks to highlight the difficulties faced by many children whose parents are incarcerated, drawing particular attention to the daily practicalities of life as a prisoner's child. The article begins by outlining the impact that the actual removal or absence of a parent from a home may have on a child, which I have referred to as the 'direct' effects. Possible moderating factors (or factors that can determine the severity of this impact) are then discussed before the indirect effects of parental incarceration are examined. I tend to view the 'indirect' effects as being those effects which are, on the part of the justice system, essentially unintentional and yet remain very significant. Creating an awareness of these 'forgotten' children may, to some degree, promote a realization that they are also essentially victims of a crime and as deserving of support as any other victims [1].

\section{Direct effects of parental incarceration}

Children separated from their parents for prolonged periods of time are known often to experience considerable emotional, behavioural and developmental problems and are typically thought to be at increased risk of learning difficulties [2]. While this might not always be the case, it is interesting to examine why it frequently tends to be so.

\subsection{Emotional/Developmental effects of parental absence}

The sudden removal of a parent from a child's life can give rise to uncertainty and may result in the disruption of a child's entire 'assumptive world' (i.e. the assumptions that cause people to feel secure [3]). The anxiety caused by such an event can be extremely unsettling for a child. One of the main differences between parental absence due to incarceration and that due to other reasons is that the loss of a parent through imprisonment can be (and often is) experienced multiple times [4]. As a result, restoring a feeling of security or re-building a new assumptive world can be even more difficult for a child whose parent is imprisoned than in cases, for example, of parental death in which the loss can only occur once. A child may find it quite difficult to cope with the uncertainty of a new situation such as life after a parent goes to prison. Miller claims that 'when challenges exceed a child's capacity to cope, emotional survival takes precedence, and meeting specific developmental tasks are interrupted' [5]. Such interruptions can have a huge bearing on the academic progression of a child.

The removal of a parent from the family home can also have an impact on how a child maintains or develops attachments in the future (see, for example, 
[6]). Understandably, it can be more difficult to trust the security of a relationship if that relationship was previously considered secure but has been suddenly disrupted. The emotional implications of this are obvious but there also may be implications for a child's educational life. Edwards asserts that:

securely attached children advance through developmental stages toward successful psychosocial and school-related functioning more efficaciously than insecurely attached children...[but] abrupt separation from a parent can negatively affect [all] children's social-emotional development [7].

\subsection{Potential loss of primary disciplinarian}

While changes in a child's behaviour may stem largely from emotional disturbances, they may be prompted by the removal of the parent who plays the role of disciplinarian in a child's life, a situation referred to by participants in, for example, Boswell and Wedge's 2002 study [8] and also Shaw's of 1987 [9]. One participant, speaking of a boy whose father was imprisoned, stated ' $[\mathrm{He}]$ feels he can do what he wants now that Dad isn't around' [8]. Regardless of the cause of the behavioural changes, research has indicated that problematic behaviour on the part of a child can reduce the likelihood of his/her academic success (see, for example, [10]).

\subsection{Potential loss of primary educator}

Similarly, the absent parent might sometimes have been the main educator within the home and/or may be the person who encouraged a child to do well at school, read, complete homework or simply be in school on time. Speaking specifically of incarcerated parents, Foster and Hagan have suggested that such an absence 'may involve...the loss of...educational opportunities..., which...may therefore limit the educational achievements of children' [11]. Admittedly, such scenarios are not always "the norm", with some criminal parents failing to play any part in their children's educational lives. However, it has long been accepted that parents are a child's primary educators and we ought not to underestimate the value of the parent/child relationship to the education of a child even if the parent is an habitual criminal. Bad people are not always bad parents or, as Boswell and Wedge once put it, there is no 'good reason to equate offending behaviour with bad parenting' [8].

\section{Moderating factors}

The impact that a parent's imprisonment has on a child clearly may be influenced by a number of moderating factors. For example, the level of parentchild contact and the quality of the parent-child relationship prior to imprisonment may obviously play a role in determining the level of disruption or anxiety experienced by a child (see, for example, [12], [13] and [14]). There is some controversy regarding the importance of the developmental stage of the child when it comes to estimating how a child will react to a parent's imprisonment. Miller claims that it is a 'major determining factor of how a child will respond' [5] while Murray, Farrington and Sekol's research ${ }^{1}$ found no differences relating to 'the child's age at the time of parental incarceration' [14]. Other possible moderating factors include the level of parent-child contact during imprisonment and a parent's overall influence on a family prior to incarceration. For example, the removal of a violent or abusive parent from a home would (most likely) have an entirely different impact on family life than the removal of a caring, gentle parent.

\section{Indirect effects of parental incarceration}

\subsection{Disruption to a child's living situation}

Absence of a parent through incarceration can prove to be a particularly difficult adjustment for a child to come to terms with, for a variety of reasons, the most important of these for future life might be that imprisonment of a parent may have an indirect impact on a child's education in a number of ways. For example, parental incarceration often results in disruption to a child's living situation. In 2009, Geller, Garfinkel, Cooper and Mincy found that children whose fathers had been incarcerated were likely to move home more often than their counterparts [15]. An (albeit extreme) example of this trend was reported by a participant in Bocknek et al.'s study who stated that she had moved five times in just one year 'as a result of her mother's illegal behaviors and imprisonment' [16]. The instability and disruption of moving home and often school in this manner can render the possibility of academic success difficult, an opinion shared by researchers such as Dallaire, Ciccone and Wilson [10].

Children of incarcerated parents are also more likely to experience changes in primary caregivers

\footnotetext{
1 This was a meta-analysis of children's antisocial behaviour, mental health, drug use and educational performance after parental incarceration.
} 
(see, for example, [15]). These alternative carers may sometimes be grandparents or other family members but care might also be given by the new partner(s) of the remaining parent. This seems to be the case particularly when fathers are imprisoned (see [9] and [4]). However, it must be said that, while much of the research emphasizes the disruptive nature of introducing new (or changing existing) caregivers for children, particularly in the early days of such a shift, alternative carers may exert a positive (as opposed to a negative) influence on children and their academic wellbeing. For example, in 2009 Cho found evidence to suggest that children whose mothers were imprisoned were less likely to be retained (or "kept back") in a class than their counterparts and suggested that this may be due to improvements in areas such as 'attendance, conduct, grades, and homework completion' possibly caused by increased involvement of new caregivers, most of whom were grandmothers [17].

\subsection{Financial strain}

A recurring theme in the literature is the negative economic impact that imprisonment of a parent often has on a family. The research suggests that the loss of a parent's financial contribution to a family (be that a legal contribution, such as a salary, or moneys that are the proceeds of crime) coupled with the additional costs associated with incarceration (such as visiting and legal costs) can dramatically reduce a household's disposable income and typically causes a family to experience economic difficulties (see, for example, [15]). Foster and Hagan claim that such financial strains make up a part of the 'cumulative disadvantage process that diminish the educational success of children' [11], with many other researchers linking economic disadvantage to development problems (see, for example, [18]).

\subsection{Unsatisfactory explanations given to children}

Children whose parents have been imprisoned are often not told the truth about the situation. In the United Kingdom in 1992, Shaw found that a third of children were told lies to explain their parents' absences while another third were told nothing at all [19]. An Irish study in 2002 reported similar findings, with $61 \%$ of parents in prison stating that their children were unaware of their whereabouts [20]. Children who find out the truth from alternative sources can experience considerable anxiety and the potential loss of trust between children and parents can result in additional suffering for children. As Miller points out, 'even when caregivers' intentions are good, they lack insight into the potentially detrimental consequences for [sic] misleading a child' [5]. These consequences can affect a child's adjustment to the entire situation and may have implications for many aspects of his/her life, including educational attainment. Similarly, vague explanations can be equally distressing for children. A prime example of this was the boy who was told that his father was in prison because he was 'in the wrong place at the wrong time'. The boy, then terrified that he, too, would be in the wrong place at the wrong time spent his days anxiously trying to figure out how he could prevent this from happening [16].

\subsection{Reactions of others to the incarceration}

All of the above disruptions and difficulties potentially experienced by a child may be exacerbated by negative reactions of those around the child, which might manifest themselves through stigma, bullying or the further withdrawal of friends from relationships with the child. Participants in numerous studies of prisoners' families have referred to the negative labels often attached to them following the imprisonment of a criminal family member (see, for example, [8] and [16]). The shame of having a family member in prison can worsen the sense of loss and disruption already referred to and may cause a child to feel alienated from his/her peers. While one might argue that younger children may not necessarily feel this shame or understand that they are being stigmatized, Miller asserts that most children are indeed 'aware of society's stigma on criminal behavior' [5] while another researcher suggests that children may be affected by stigma regardless of whether or not they are 'cognizant of the stigma attached to incarceration' [4].

There has been some speculation that imprisonment of a family member might carry less of a stigma (and perhaps even a sense of pride) in some regions due to socio-economic or maybe even cultural factors (see, for example, [17]). The families of IRA members are often seen as heroic victims themselves in certain Irish communities, for example, and the same can be so in other groups and other countries. However, the majority of the available research seems to suggest that this is not the case, with Nesmith and Ruhland stating that children in their study were 'keenly aware of the negative assumptions that might be made about them because they had a parent in prison' [21].

According to this research, many children whose parents are imprisoned experience some form of bullying due to the incarceration and, in some cases, may even develop a reluctance to go to school as a result (see, for example, [13] and [8]). Even when this 
is not the case, people may withdraw from friendships with children of incarcerated parents or, particularly in the case of younger children, parents might 'pull [them]...away from children of inmates, with little or no explanation' [22]. This can be extremely distressing for children of imprisoned parents. Being stigmatized or feeling alienated in such a way can have implications for how successfully a child functions in school and may thus have an impact on a child's academic achievement (see, for example, [7]).

In an attempt to avoid being stigmatized or bullied children (those who actually know the truth) sometimes keep their parents' imprisonment secret from their peers. Often this secrecy is their own idea but, alternatively, they might have been ordered by the parent/carer "on the outside" to keep the secret and are thus pushed into what Chui calls a 'forced silence' [13]. Either way, the pressure of keeping the truth hidden, along with the resultant absence of a potentially invaluable support system, means that many children must suffer in silence.

\subsection{Behavioural reactions of children with imprisoned parents}

Children's reactions to any or all of the above have been shown, in turn, to cause changes in behavior. Much existing literature has noted a deterioration of children's behaviour and/or increases in aggression levels (reported mainly by parents, caregivers and teachers) following parents' imprisonment (see, for example, [12]). However, while such changes seem to be extremely common, there has been controversy as to whether the incarceration of parents is essentially the cause of such developments. Murray et al. warn that 'firm causal conclusions cannot be drawn' [14]. This is understandable when one considers that each individual case is different. A child whose imprisoned parent was not previously resident in the family home and who does not experience any of the indirect effects we have discussed above may obviously have a different, less disruptive experience than a child whose (disciplinarian) parent has been removed from the home abruptly and who must deal with some or all of these effects. Therefore, while many children may have behavioural reactions to the event, it is impossible to say that all children will do so and we cannot conclude that placing a parent in prison actually directly causes deterioration of children's behaviour. Nonetheless, difficult behaviour can have a negative impact on a learning environment. As Dallaire et al. put it, 'behavioural or emotional problems associated with parental incarceration can negatively influence children's academic success' [10].

\subsection{Implications for a child's academic performance}

There is also considerable controversy regarding the effect of parental incarceration on children's concentration levels and academic achievement. While, for the same reasons as with behavioural changes, we cannot conclude definitively that alterations to concentration levels or changes in academic achievement are caused by parents' imprisonment, most research in the area has agreed that children of imprisoned parents are at increased risk of academic failure or, at least, a deterioration of academic performance (see, for example, [10]). However, Murray et al. carried out 'rigorous studies' in 2012 and concluded that parental incarceration was not associated with increased risk for poor academic performance [14] while Cho's research also found that there was no change in the reading and math standardized test scores of children whose mothers were imprisoned [23]. Other (perhaps less controversial) studies have indicated that parental imprisonment is associated with increased attention problems (see, for example, [9] and [12]), and these might reasonably lead to academic problems.

\subsection{Potential positive effects of parental incarceration}

Of course, parental imprisonment may occasionally have some positive effects such as increased support from family or friends, the development of children's coping skills or increased resilience in the face of adverse conditions. Children such as those in Nesmith and Ruhland's 2008 study reported turning to sports, theatre or religion to help them to cope and many said that these activities provided an outlet for their anger, built confidence, gave them something else to focus on and sparked new friendships [21]. It is unclear, however, if the "good" effects here outweigh the "bad" or if they simply serve to make the bad effects more manageable.

\section{Conclusion}

Overall, Purvis succinctly sums up existing literature in stating 'research resoundingly confirms that the incarceration of a parent has devastating effects on children' [24]. Imprisonment of a parent certainly means much more to a child than simply the removal of a parent from the home. Aside from the direct effects of doing so, there are numerous indirect effects that can have an impact on a child's life at every level and have serious implications for his/her 
educational and developmental wellbeing. As children progress through the education system, reports and results follow them, meaning that short-term disturbances in educational attainment, behaviour or concentration levels can potentially have a long-term impact on their futures in the education system and beyond. Incarceration of a parent can, thus, influence a child's life chances and lead to the question "Whose sentence is it?".

\section{References}

[1] Matthews, J. (1983). Forgotten victims. London: National Association for the Care and Resettlement of Offenders.

[2] Jee, S.H., Conn, K.M., Nilsen, W.J., Szilagyi, M.A., Forbes-Jones, E., \& Halterman, J.S. (2008). Learning difficulties among children separated from a parent. Ambulatory Pediatrics, 8(3), pp. 163-168.

[3] Parkes, C.M. (1988). Bereavement as a psychosocial transition: Processes of adaptation to change. Journal of Social Issues, 44(3), pp. 53-65.

[4] Wildeman, C. (2010). Paternal incarceration and children's physically aggressive behaviors: Evidence from the Fragile Families and Child Wellbeing Study. Social Forces, 89(1), pp. 285-309.

[5] Miller, K.M. (2006). The impact of parental incarceration on children: An emerging need for effective interventions. Child and Adolescent Social Work Journal, 23(4), pp. 472486.

[6] Poehlmann, J. (2005). Representations of attachment relationships in children of incarcerated mothers. Child Development, 76(3), pp. 679-696.

[7] Edwards, O.W. (2009). A choice theory teaching and learning model for working with children of prisoners. Educational Psychology in Practice, 25(3), pp. 259-270.

[8] Boswell, G., \& Wedge, P. (2002). Imprisoned fathers and their children. London: Jessica Kingsley.

[9] Shaw, R. (1987). Children of imprisoned fathers. London: Hodder and Stoughton.

[10] Dallaire, D.H., Ciccone, A., \& Wilson, L.C. (2010). Teachers' experiences with and expectations of children with incarcerated parents. Journal of Applied Developmental Psychology, 31(4), pp. 281-290.

[11] Foster, H., \& Hagan, J. (2007). Incarceration and intergenerational social exclusion. Social Problems, 54(4), pp. 399-433.

[12] Geller, A., Cooper, C.E., Garfinkel, I., Schwartz-
Soicher, O., \& Mincy, R.B. (2012). Beyond absenteeism: Father incarceration and child development. Demography, 49(1), pp. 49-76.

[13] Chui, W.H. (2010). 'Pains of imprisonment': Narratives of the women partners and children of the incarcerated. Child and Family Social Work, 15(2), pp. 196-205.

[14] Murray, J., Farrington, D.P., \& Sekol, I. (2012). Children's antisocial behavior, mental health, drug use, and educational performance after parental incarceration: A systematic review and meta-analysis. Psychological Bulletin, 138(2), pp. 175-210.

[15] Geller, A., Garfinkel, I., Cooper, C.E., \& Mincy, R.B. (2009). Parental incarceration and child well-being: Implications for urban families. Social Science Quarterly, 90(5), pp. 1186-1202.

[16] Bocknek, E., Sanderson, J., \& Britner, P. (2009). Ambiguous loss and posttraumatic stress in school-age children of prisoners. Journal of Child and Family Studies, 18(3), pp. 323-333.

[17] Cho, R.M. (2009). Impact of maternal imprisonment on children's probability of grade retention. Journal of Urban Economics, 65(1), pp. 11-23.

[18] Kiernan, K.E., \& Huerta, M.C. (2008). Economic deprivation, maternal depression, parenting and children's cognitive and emotional development in early childhood. The British Journal of Sociology, 59(4), pp. 783-806.

[19] Shaw, R. (1992). Imprisoned fathers and the orphans of justice. In R. Shaw (Ed.), Prisoners' children: What are the issues? (pp. 41-49). London: Routledge.

[20] King, D. (2002). Parents, children and prison: Effects of parental imprisonment on children. Dublin: Centre for Social and Educational Research.

[21] Nesmith, A., \& Ruhland, E. (2008). Children of incarcerated parents: Challenges and resiliency, in their own words. Children and Youth Services Review, 30(10), pp. 1119-1130.

[22] Breen, P.A. (1995). Bridging the barriers. Corrections Today, 57(7), pp. 98-99.

[23] Cho, R.M. (2009). The impact of maternal imprisonment on children's educational achievement: Results from children in Chicago public schools. Journal of Human Resources, 44(3), pp. 772-797.

[24] Purvis, M. (2013). Paternal incarceration and parenting programs in prison: A review paper. Psychiatry, Psychology and Law, 20(1), pp. 9-28. 